\title{
Virtual Reality Language Lab of Second Language Learning Based on J Bruner's Discovery Learning and Self-Efficacy Theory-Literature Review and Solution Improvement
}

\author{
Zhiyu Zhao \\ Zhejiang University of Technology, Hangzhou, 310023, China
}

\begin{abstract}
Language learning has gradually involved innovative technology such as the use of $3 D$ virtual worlds, which can enhance learners' immersion through improved engagement with the help of their motivational components. Immersion in the target language environment for example English, Spanish, French and German environment provides maximum exposure to the communicative use, offering the opportunity to learners' active creativity. Since real travel is expensive and impractical, virtual travel in the virtual reality language lab provides them a brand new opportunity. Adopting the literature research method, this paper aims to figure out the optimum time duration and time frequency for most language learners to spend in the virtual world. Based on Discovery Learning and Self-efficacy Theory, we tend to focus on the behaviors of the learner in the virtual world, such as how they express themselves in second language and acquire daily expressions with the help of Unity3D to design and develop $3 D$ virtual worlds and the EEG (electroencephalogram) equipment to reflect changes in the neural representation of the task environment. In order to find a possible relationship between communicative activities and the learning theories of Discovery Learning and Self-efficacy Theory, correlative analysis and principal component analysis were performed. According to this research, we can effectively limit the time and frequency of the immersion in the second language environment and promote the efficiency.
\end{abstract}

Keywords: Virtual reality, Second Language Learning, Discovery learning, Self-efficacy theory, EEG (electroencephalogram).

\section{Introduction}

Before the laboratory, Caillois indicates the immanent complexities and advantages of digital gaming and magnificent chances it provides for efficient, pregnant learning across disciplines in 1961 [1]. On the aspect of educational games, in 2017.12, Julie M. Sykes focuses on how to use digital games in the context language learning and finds some solutions to increase approaches to community-based and commercial games, as well as to make consequential incorporation of virtual reality [2]. In 2020.1, Yifan Wang developed VR-Rides, an object-oriented programming module focused on the development of experiment-oriented VR games [3].

On the aspect of educational research, in 2019.5, Li Wei Chen, compares the performance between sequence (traditional) and context based teaching designs along using a self developed VR computer numerical control (VRCNC) training environment with three kinds of evaluation solutions providing a comprehensive support for the context based teaching design along with the VRCNC in equipment education [4]. Another platform developed by JANUS S. LIANG, is an immersive VR automotive driving learning (imseADL) based on a web-based collaborative design environment at the YTIT without physically visiting these facilities [5]. Jyun Chen Chen conducts a study combined virtual reality technology, the 6E model, and STEM education to create a hands on activity aimed at improving students' progress in the way of "learning by doing" [6].

Apart from VR, T.Y. Liu develops a sensor and handheld augmented reality (AR)-supported ubiquitous learning (u-learning) environment named the Hand held English Language Learning Organization (HELLO), gearing to enhance students' skills in language learning [7].

Above all, the VR language laboratory constructions are not very popular due to the limit of technology and time in recent years, so large amount of study is urgently needed to find out the suitable way to develop a virtual reality language learning laboratory to help students to improve their second language skills.

\section{Research Problems and Values}

\subsection{Research Issues}

This article attempts to use a VR language learning laboratory to help second language learners to improve their learning efficiency as well as figuring out the optimum time duration and time frequency for most language learners to spend in the virtual world independently and formulating an individual program for each student. Taking the observations of some traditional education examples into account, we find that students have various accents based on their birthplaces and are influenced by their intrinsic mindsets of speaking Chinese, which results in their lack of self-confidence in learning English and eventually the dissatisfied results.

According to the above research reviews and real situations, the research issues are as follows:

1) Did the students using the VR language learning laboratory have better learning achievements than those learning with the conventional learning approach? 
2) Did the students using the VR language learning laboratory have better learning motivation than those learning with the conventional learning approach?

3) Did the students using the VR language learning laboratory have better self-efficacy than those learning with the conventional learning approach?

4) Did the students using the VR language learning laboratory have higher problem-solving tendency than those learning with the conventional learning approach?

5) Did the students using the VR language learning laboratory have lower cognitive load than those learning with the conventional learning approach?

\subsection{Values}

Language learning is not only words, sentences and grammar, but a deep understanding of the cultural background also counts. So the construction of virtual reality language learning laboratory is of great significance, solving the problems of insufficient time and large expenses of real travels of students. We have to attach equal importance to verbal expressions and exams, by using the lab to make the oral test more efficient and convenient, at the same time limiting the time and frequency of the immersion in the second language environment, so as to achieve the goal of improve students' second language learning outcomes in various aspects.

\section{The Solutions from Literatures}

\subsection{Effects of Applying A VR-Based Two-Tier Test Strategy to Promote Elementary Students' Learning Performance in A Geology Class}

The solution of the research was two-tier test strategy, which involved a conception that was divided into two levels. The first-tier question figured out students' basic knowledge, while second one was a development of the former, concerning to background reasons of their choices. The obvious benefit of a two-tier test was better understandings of students' real thoughts, avoiding misunderstandings or the wrong concepts about the questions.

3.2 Virtual Reality in Problem-based Learning Contexts: Effects on the Problem-Solving Performance, Vocabulary Acquisition and Motivation of English Language Learners

The research founded on the PBL, which can facilitate students' meta-cognitive skills as they are faced to define a problem, search for information, analyze data, construct hypotheses and implement solutions. The present study thus focused on building on the affordances of VR technology to establish a VR-assisted PBL context for EFL learners.

3.3 Immersive Virtual Reality or Auditory Text First? Effects of Adequate Sequencing and Prompting on Learning Outcome

The article addressed the importance of cognitive learning processes in VRLEs. When learners have abundant resources to process all relevant information, they can build a coherent mental model to elucidate consequences from manipulating one component onto another, which was easily resulted in cognitive overload. To avoid this overload and to enable students to process the content according to causalities, the directory pattern of the VRLE needs to be implemented.

\section{4Experiments' Data and Analysis}

4.1 Effects of Applying A VR-Based Two-Tier Test Strategy to Promote Elementary Students' Learning Performance in A Geology Class

As shown in Figure 1, the experimental group used the two-tier test strategy VR guiding system to learn the content while the other group learned with the conventional VR guiding system learning approach [8].

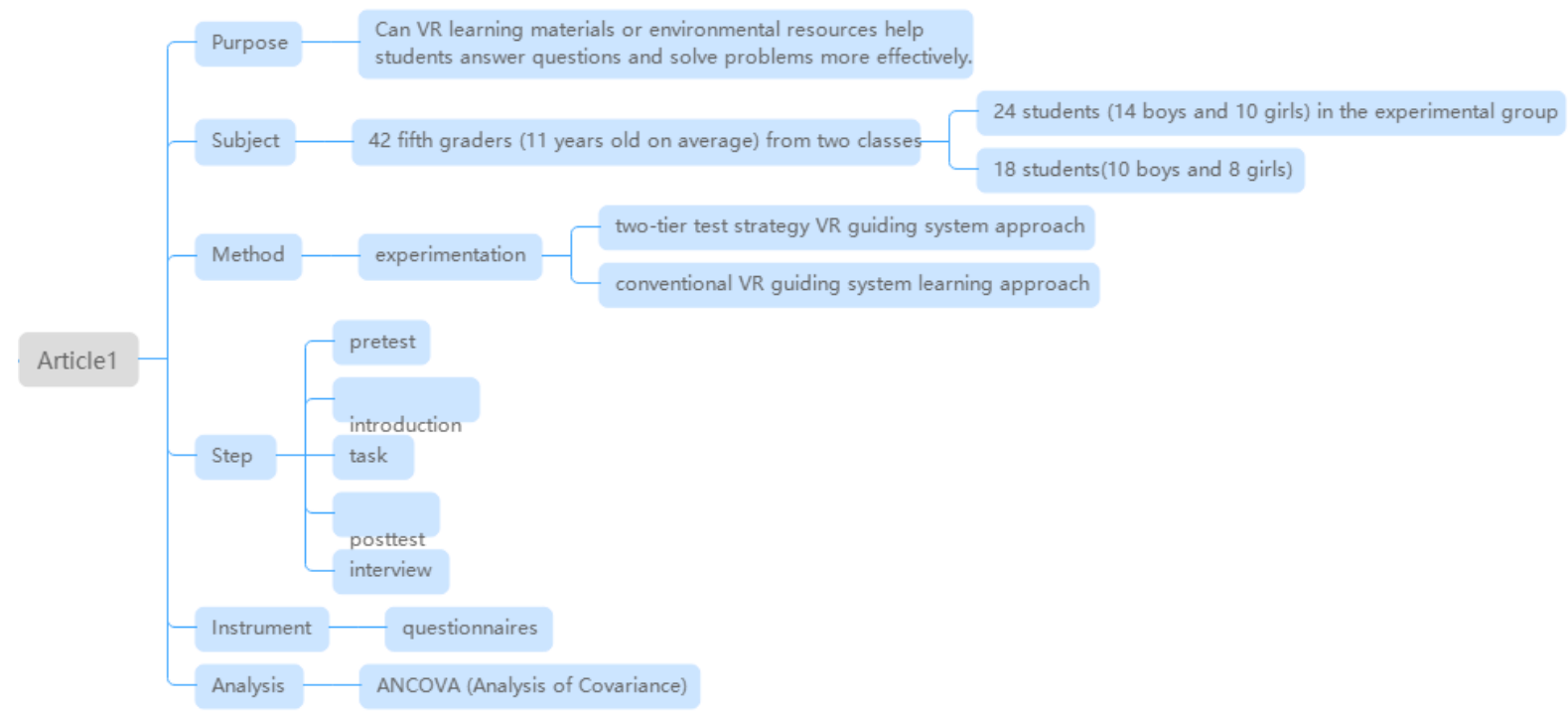

Figure 1: Outline of Article 1 
Before the experiment started, the students needed to complete the pre-questionnaires as well as a pretest to evaluate their basic knowledge. The next step is introduction and guidance of the two-tier test VR system and the conventional VR guiding system separately according to their groups. Both groups had 50 minutes to finish their learning tasks. After the learning job, all the students were required to take the posttest and the post-questionnaires. Eventually, five students from each group were randomly selected for an interview. The whole process is shown in Figure 2.

Analysis of learning achievements of the knowledge test is shown in Table 1. Analysis of learning motivation is shown in Table 2. Analysis of self-efficacy is shown in Table 3. Analysis of problem-solving tendency is shown in Table 4. Analysis of cognitive load is shown in Table 5. Behavioral sequential analysis of the two-tier test VR system is shown in Table 6 and Figure 3.

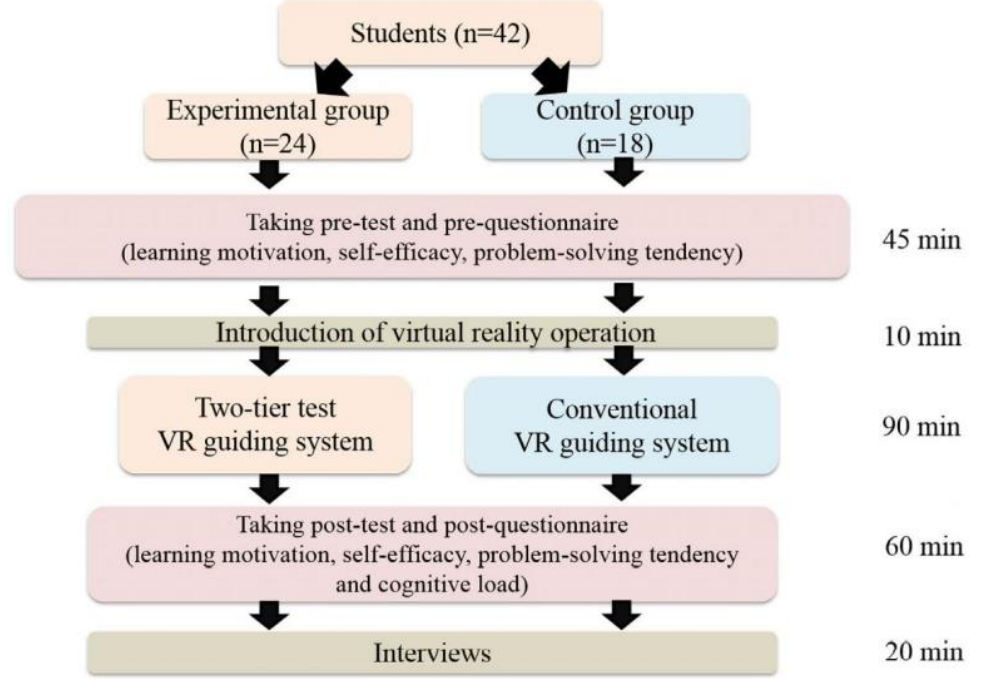

Figure 2: The experimental process

Table 1: The ANCOVA result of learning achievement

\begin{tabular}{|c|c|c|c|c|c|c|c|}
\hline Group & $\mathrm{N}$ & Mean & SD & Adjusted mean & SE & F & $\eta^{2}$ \\
\hline Experimental group & 24 & 72.71 & 10.31 & 72.99 & 2.05 & $4.92^{*}$ & 0.11 \\
\hline Control group & 18 & 66.39 & 10.72 & 66.01 & 2.37 & & \\
\hline
\end{tabular}
$* \mathrm{p}<.0 .5$.

Table 2: The ANCOVA result of learning motivation

\begin{tabular}{|c|c|c|c|c|c|c|c|}
\hline Group & $\mathrm{N}$ & Mean & SD & Adjusted mean & SE & $\mathrm{F}$ & $\eta^{2}$ \\
\hline Experimental group & 24 & 3.95 & 0.79 & 3.83 & 0.14 & $5.881^{*}$ & 0.13 \\
\hline Control group & 18 & 3.11 & 0.52 & 3.28 & 0.16 & & \\
\hline
\end{tabular}

Table 3: The ANCOVA result of self-efficacy

\begin{tabular}{|c|c|c|c|c|c|c|c|}
\hline Group & $\mathrm{N}$ & Mean & SD & Adjusted mean & SE & F & $\eta^{2}$ \\
\hline Experimental group & 24 & 3.61 & 0.76 & 3.47 & 0.14 & $4.42^{*}$ & 0.10 \\
\hline Control group & 18 & 2.81 & 0.71 & 2.99 & 0.17 & & \\
\hline
\end{tabular}
$* \mathrm{p}<.0 .5$.

Table 4: The ANCOVA result of cognitive load

\begin{tabular}{|c|c|c|c|c|c|c|c|}
\hline Group & $\mathrm{N}$ & Mean & SD & Adjusted mean & SE & $\eta^{2}$ & 0.16 \\
\hline Experimental group & 24 & 4.17 & 0.87 & 4.05 & $6.15^{*}$ & 0.02 \\
\hline Control group & 18 & 3.26 & 0.41 & 3.38 & 0.19 & \\
\hline
\end{tabular}
$* \mathrm{p}<.0 .5$.

Table 5: The t-test result of problem-solving tendency

\begin{tabular}{|c|c|c|c|c|}
\hline Group & $\mathrm{N}$ & Mean & SD & $\mathrm{t}$ \\
\hline Experimental group & 24 & 2.10 & 0.75 & -1.62 \\
\hline Control group & 18 & 2.56 & 0.98 & \\
\hline
\end{tabular}

Table 6: Adjusted residuals table of $Z$ values in the serial behavior analysis of using the two-tier test VR system

\begin{tabular}{|c|c|c|c|c|c|c|c|}
\hline Behaviors & AQ & WL & SR & WA & PQ & EQ & $\mathrm{CS}$ \\
\hline AQ & -4.64 & -15.61 & -8.89 & 16.59 & 32.33 & -2.97 & -7.54 \\
\hline WL & 9.34 & 1.67 & 6.19 & 1.74 & -7.20 & -3.74 & -13.39 \\
\hline SR & -1.84 & 18.61 & 2.46 & -7.89 & -6.22 & -3.05 & -10.93 \\
\hline WA & -5.26 & -9.19 & 22.27 & 1.52 & -6.40 & 7.99 & -6.51 \\
\hline PQ & -7.22 & -11.63 & -9.69 & -6.40 & -7.02 & -2.21 & 46.45 \\
\hline EQ & 2.90 & -1.43 & -2.64 & -1.46 & -2.21 & 22.85 & -2.50 \\
\hline $\mathrm{CS}$ & 5.65 & 13.32 & -10.58 & -6.99 & -7.67 & -0.49 & 2.00 \\
\hline
\end{tabular}

$* \mathrm{p}<.0 .5$. 


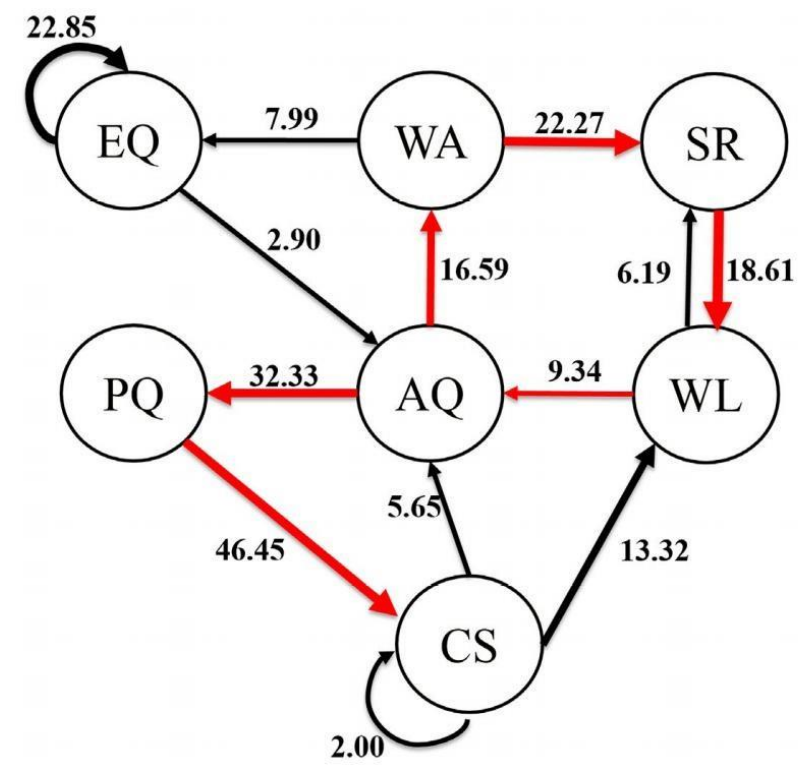

Figure 3: The sequential path of the two-tier test VR guiding system Interview results

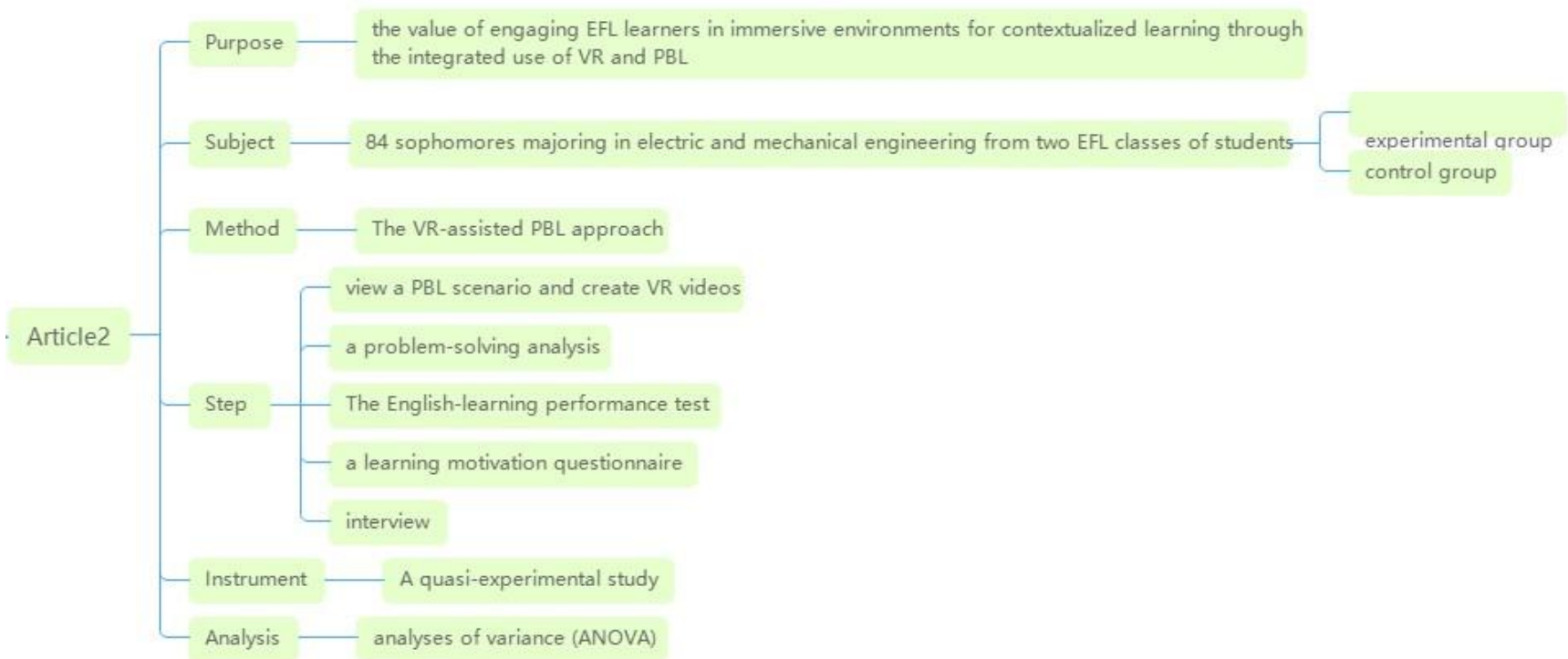

Figure 4: Outline of Article 2

The experimental group students concentrated more on learning and were more willing to complete the learning tasks while the control group students pay attention to complete all the learning tasks, ignoring the environmental information provided.

4.2 Virtual Reality in Problem-based Learning Contexts: Effects on the Problem-Solving Performance, Vocabulary Acquisition and Motivation of English Language Learners

As we can see from Figure 4, With 84 engineering majors in English learning for specific purposes were randomly divided into the experimental group and the control group. Both groups viewed a PBL scenario and then created VR videos concerned with the given problems [9]. The differences were the experimental group used VR technology assistance while the control group were on their own efforts. The experiment collected data from posttests and sample interviews with analyses of variance (ANOVA).

Effect on problem-solving performance is shown in Table 7. Effect on English vocabulary acquisition is shown in Table 8. Effect on English vocabulary acquisition is shown in Table 9.

The chosen participants gave additional support for the statistics. Both groups of students understood the significance of PBL and perceived it actively. The experimental students underscored the PBL approach and confirmed that they had become more willing to learn professional English.

Table 7: Results of ANOVA for problem-solving performance

\begin{tabular}{|c|c|c|c|c|c|c|}
\hline Group & $\mathrm{N}$ & $\mathrm{Mean}$ & $\mathrm{SD}$ & $\mathrm{F}$ & $\mathrm{p}$ & $\eta^{2}$ \\
\hline $\begin{array}{c}\text { Experimental } \\
\text { group }\end{array}$ & 42 & 58.32 & 11.89 & 3.68 & 0.06 & 0.04 \\
\hline Control group & 42 & 52.75 & 8.35 & & & \\
\hline
\end{tabular}


Table 8: Results of ANCOVA for English vocabulary acquisition

\begin{tabular}{|c|c|c|c|c|c|c|c|c|c|}
\hline \multirow[b]{2}{*}{ Assessment } & \multicolumn{3}{|c|}{ Experimental group } & \multicolumn{3}{|c|}{ Control group } & \multirow[b]{2}{*}{$\mathrm{F}$} & \multirow[b]{2}{*}{$\mathrm{p}$} & \multirow[b]{2}{*}{$\eta^{2}$} \\
\hline & Mean & SD & Adj.M & Mean & SD & Adj.M & & & \\
\hline Pre-test & 55.35 & 20.61 & 48.93 & 48.33 & 13.95 & 43.98 & $15.89 * *$ & 0.00 & 0.16 \\
\hline Post-test & 88.38 & 12.20 & 84.58 & 77.14 & 13.64 & 72.89 & & & \\
\hline
\end{tabular}

* $\mathrm{p}<.0 .5$.

Table 9: Results of ANOVA for English learning motivation

\begin{tabular}{|c|c|c|c|c|c|c|c|}
\hline \multirow{2}{*}{ Dimension } & \multicolumn{2}{|c|}{ Experimental group } & \multicolumn{2}{|c|}{ Control group } & \multicolumn{2}{c|}{} \\
\cline { 2 - 8 } & Mean & SD & Mean & SD & F & p & $\eta^{2}$ \\
\hline Ideal L2 self & 4.51 & 0.97 & 4.11 & 0.87 & 3.88 & 0.05 & 0.05 \\
\hline Ought-to L2 self & 4.39 & 0.87 & 4.14 & 0.83 & 1.67 & 0.20 & 0.02 \\
\hline Promotion-instrumentality & 4.68 & 0.67 & 4.24 & 0.95 & $5.97^{*}$ & 0.02 & 0.06 \\
\hline Prevention- instrumentality & 4.48 & 0.82 & 4.21 & 0.82 & 2.20 & 0.14 & 0.03 \\
\hline Attitudes toward English & 4.44 & 0.85 & 3.98 & 0.99 & $5.20^{*}$ & 0.03 & 0.06 \\
\hline English anxiety & 4.29 & 0.79 & 4.13 & 0.94 & 1.83 & 0.18 & 0.07 \\
\hline
\end{tabular}

$* \mathrm{p}<.0 .5$.

English anxiety

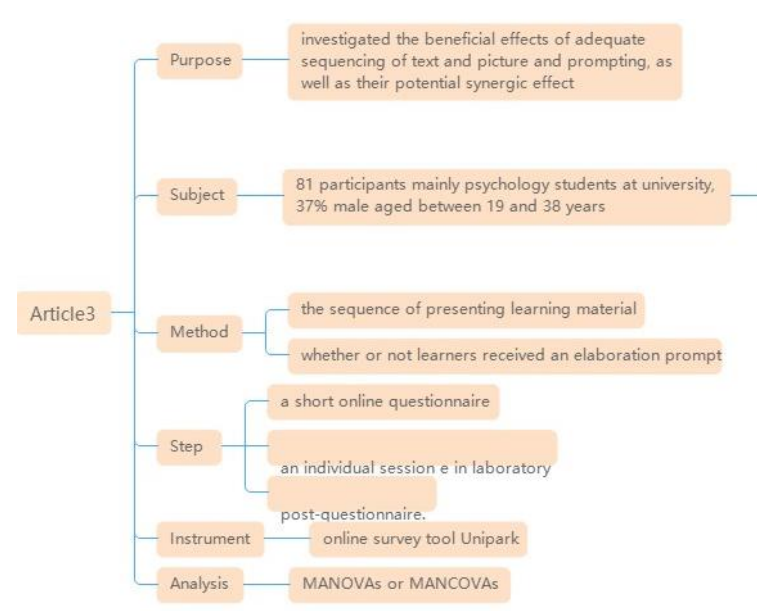

Figure 5: Outline of Article 3

4.3 Immersive Virtual Reality or Auditory Text First? Effects of Adequate Sequencing and Prompting on Learning Outcome

Demonstrated by Figure 5, different from the above two articles, this one use a method of a $2 \times 2$ between-subject design, arranging four experimental groups with different dependency in prompt and auditory text or VR animation, aiming to find out the impacts of adequate sequencing of text, picture and prompting, as well as their potential cooperative influence in an immersive virtual reality learning environment. As for the procedure, a short questionnaire was taken online, followed by an individual session e in laboratory, and finally the post-questionnaire. MANOVAs replaced multiple ANOVAs to show the results magnificently [10].

Here is the impact of sequencing and prompting on learning outcome is shown in Table 10 and Table 11.

Table 10: Means and standard deviations of the experimental groups on all levels of learning outcome

\begin{tabular}{|c|c|c|c|c|}
\hline \multirow{2}{*}{} & \multicolumn{2}{|c|}{ VR animation first } & \multicolumn{2}{|c|}{ Auditory text first } \\
\cline { 2 - 5 } & \multicolumn{2}{|c|}{ M(SD) } & \multicolumn{2}{c|}{ M(SD) } \\
\cline { 2 - 5 } & With prompt & Without prompt & With prompt & Without prompt \\
\cline { 2 - 5 } & $\mathrm{n}=20$ & $\mathrm{n}=22$ & $42.85(10.85)$ & $\mathrm{n}=19$ \\
\hline Overall(\%) & $43.71(11.27)$ & $65.98(13.14)$ & $61.23(14.12)$ & $60.09(13.49)$ \\
\hline Knowledge(\%) & $67.07(23.64)$ & $68.25(16.87)$ & $35.79(13.05)$ & $34.50(16.69)$ \\
\hline Comprehension(\%) & $39.09(15.09)$ & $41.25(25.97)$ & $28.29(11.67)$ & $22.50(11.89)$ \\
\hline Application(\%) & $25.00(12.79)$ & $20.04(15.55)$ & & \\
\hline
\end{tabular}

Table 11: Results of the MANCOVA with the different levels of learning outcome and simple contrasts for sequence and prompting, with verbal ability and prior knowledge as covariates

\begin{tabular}{|c|c|c|c|c|c|c|c|c|c|c|c|}
\hline \multicolumn{4}{|c|}{ Knowledge } & \multicolumn{3}{c|}{ Comprehension } & \multicolumn{5}{c|}{ Application } \\
\hline & $\mathrm{F}(1,68)$ & $\mathrm{P}$ & $\eta_{\text {partial }}^{2}$ & & $\mathrm{~F}(1,68)$ & $\mathrm{P}$ & $\eta_{\text {partial }}^{2}$ & & $\mathrm{~F}(1,68)$ & $\mathrm{P}$ & $\eta_{\text {partial }}^{2}$ \\
\hline Verbal ability & 8.37 & $0.005^{* *}$ & 0.110 & Verbal ability & 0.01 & 0.917 & $<0.001$ & Verbal ability & 0.33 & 0.568 & 0.005 \\
\hline $\begin{array}{c}\text { Prior } \\
\text { Knowledge }\end{array}$ & 0.07 & 0.792 & 0.001 & $\begin{array}{c}\text { Prior } \\
\text { Knowledge }\end{array}$ & 1.65 & 0.203 & 0.024 & $\begin{array}{c}\text { Prior } \\
\text { Knowledge }\end{array}$ & 5.01 & $0.029^{*}$ & 0.069 \\
\hline Prompt & 0.45 & 0.504 & 0.007 & Prompt & 0.12 & 0.732 & 0.002 & Prompt & 5.89 & $0.018^{*}$ & 0.080 \\
\hline Sequence & 8.77 & $0.004^{* *}$ & 0.114 & Sequence & 2.54 & 0.116 & 0.036 & Sequence & 2.20 & 0.143 & 0.031 \\
\hline $\begin{array}{c}\text { Prompt } \times \\
\text { Sequence }\end{array}$ & 1.74 & 0.191 & 0.025 & $\begin{array}{c}\text { Prompt } \times \\
\text { Sequence }\end{array}$ & 0.58 & 0.447 & 0.009 & $\begin{array}{c}\text { Prompt } \times \\
\text { Sequence }\end{array}$ & 0.40 & 0.525 & 0.006 \\
\hline
\end{tabular}

\footnotetext{
$* * * \mathrm{p}<0.0001 ; * * \mathrm{p}<0.001 ; * \mathrm{p}<0.05$.
} 


\section{Conclusion and Future Plan}

5.1 Effects of Applying A VR-based Two-tier Test Strategy to Promote Elementary Students' Learning Performance in A Geology Class

Accordingly, the two-tier test VR guiding system made students more motivated and confident to complete the learning tasks, with behaviors of checking the learning materials provided by the VR system. In contrast, the control group reported that the VR guiding system was more like a question competition.

In the future, it's suggested to expand the experimental time and the number of the samples, aiming not only to improve students' learning results and motivation but also their high-level insights.

5.2 Virtual Reality in Problem-based Learning Contexts: Effects on the Problem-solving Performance, Vocabulary Acquisition and Motivation of English Language Learners

The study revealed the magnificent positive effect of the VR-assisted PBL approach on the engineering sophomores' specialized English vocabulary knowledge and motivating, sustaining their interests in learning English in the future.

The further research should focus on a wider range and size of students of different majors with more specific assessments, such as cloze tests in writing forms.

5.3 Immersive Virtual Reality or Auditory Text First? Effects of Adequate Sequencing and Prompting on Learning Outcome

Preceding the above analyses, it can be concluded that the groups with picture-first better performed than text-first one and VR animation better than auditory. There's a significant difference of prompts but not for knowledge and comprehension level. The synergetic effect of both VR animation first and prompts on learning outcome was not supported.

As for the future study, different format such as written text, large sample size and long duration of learning can be adopted. In addition, free exposure to the contents, prompts before or during the learning and different measurements are also recommended.

\section{Global Comparison Analysis}

As showed in Table 12, combining the achievements of the three articles, as for the pedagogical field, they all have the same goal of improving their leaning performance and motivation through the approach of two-tier test strategy, problem-based learning field, three literatures all use virtual reality in their research. Relative equipment such as Virtual Reality Learning Environments (VRLEs) and VR guiding system which promote a sense of immersion by providing exploration in three-dimensional (3D) space compared with the traditional educational methods.

On the other hand, we can't ignore the shortcomings of them. They all did research on a relatively small sample of participants in one major, thus the experimental reliability may score high but the validity turned out to be unsatisfying. Additionally, the expense of time is rather short, which added the uncertain and excepted situations. Moreover, various kinds of assessments will inevitably result in deviations of the consequences since there's no consistent assessment.

Table 12: Advantages and Shortcomings of the three literatures

\begin{tabular}{|l|l|l|}
\hline \multicolumn{1}{|c|}{ Course content } & \multicolumn{1}{|c|}{ Achievements } & \multicolumn{1}{c|}{ Limitations } \\
\hline $\begin{array}{l}\text { "Erosion and } \\
\text { deposition" unit of the } \\
\text { elementary school } \\
\text { natural science course. }\end{array}$ & $\begin{array}{l}\text { The two-tier test VR } \\
\text { guidance system } \\
\text { improved the students' } \\
\text { learning achievement, } \\
\text { enhanced their learning } \\
\text { motivation }\end{array}$ & $\begin{array}{l}\text { Improve students' } \\
\text { learning outcomes, } \\
\text { motivation and } \\
\text { high-level thinking } \\
\text { skills. }\end{array}$ \\
\hline $\begin{array}{l}\text { A main objective of } \\
\text { enhancing their } \\
\text { specialized vocabulary } \\
\text { knowledge. }\end{array}$ & $\begin{array}{l}\text { Highlight the value of } \\
\text { engaging EFL learners } \\
\text { in immersive } \\
\text { environments for } \\
\text { contextualized learning } \\
\text { through the integrated } \\
\text { use of VR and PBL. }\end{array}$ & $\begin{array}{l}\text { Engaging learners in } \\
\text { applying their target } \\
\text { language to solve } \\
\text { problems in authentic } \\
\text { workplace situations } \\
\text { through the immersion } \\
\text { affordance available in } \\
\text { VR. }\end{array}$ \\
\hline $\begin{array}{l}\text { A first-semester } \\
\text { university course } \\
\text { teaching basics about } \\
\text { robotics. }\end{array}$ & $\begin{array}{l}\text { VR animation first } \\
\text { supported learners at the } \\
\text { knowledge level, while } \\
\text { prompting supported } \\
\text { learners at the } \\
\text { application level. } \\
\text { No synergic effect of } \\
\text { adequate sequencing and } \\
\text { prompting on learning } \\
\text { outcome. }\end{array}$ & $\begin{array}{l}\text { Long-term effects of } \\
\text { adequate sequencing and } \\
\text { prompting or different } \\
\text { approaches to measuring } \\
\text { mental models. }\end{array}$ \\
\hline
\end{tabular}

\section{Solution Improvement}

\subsection{Solution Design}

Above all, this study adds Discovery Learning and Self-efficacy Theory to polish its uniqueness. Constructivism, including Discovery Learning Theory, provides approaches to learning focus on learning environments in which students get the opportunity to construct knowledge themselves, and negotiate this knowledge with others [11], constructing their own knowledge structure in their own way. By the mean of Self-efficacy Theory, it means that at the start of the learning of second language, teachers do not need to face with learners of wide-ranging language proficiency any more, which leads to difficulties in ensuring appropriate progress for them all. Combined with VR equipment, linguistic development can be considerably improved because of unlimited exposure to the second language environment in the VR language learning laboratory. Details are shown in Figure 6. 


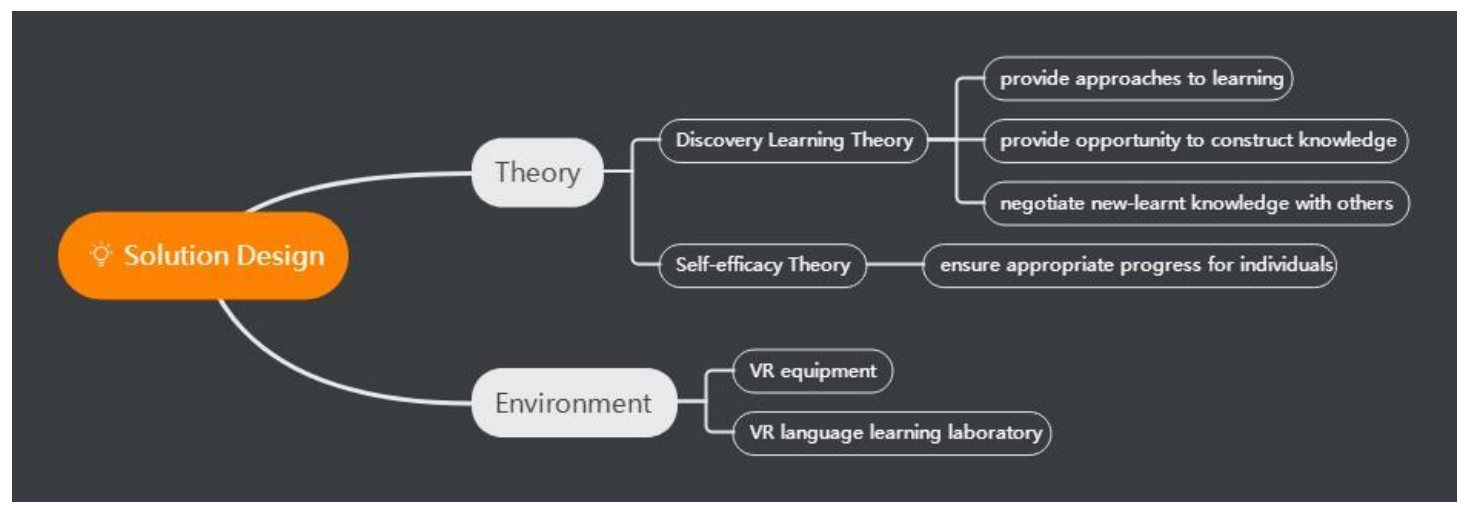

Figure 6: Solution Design

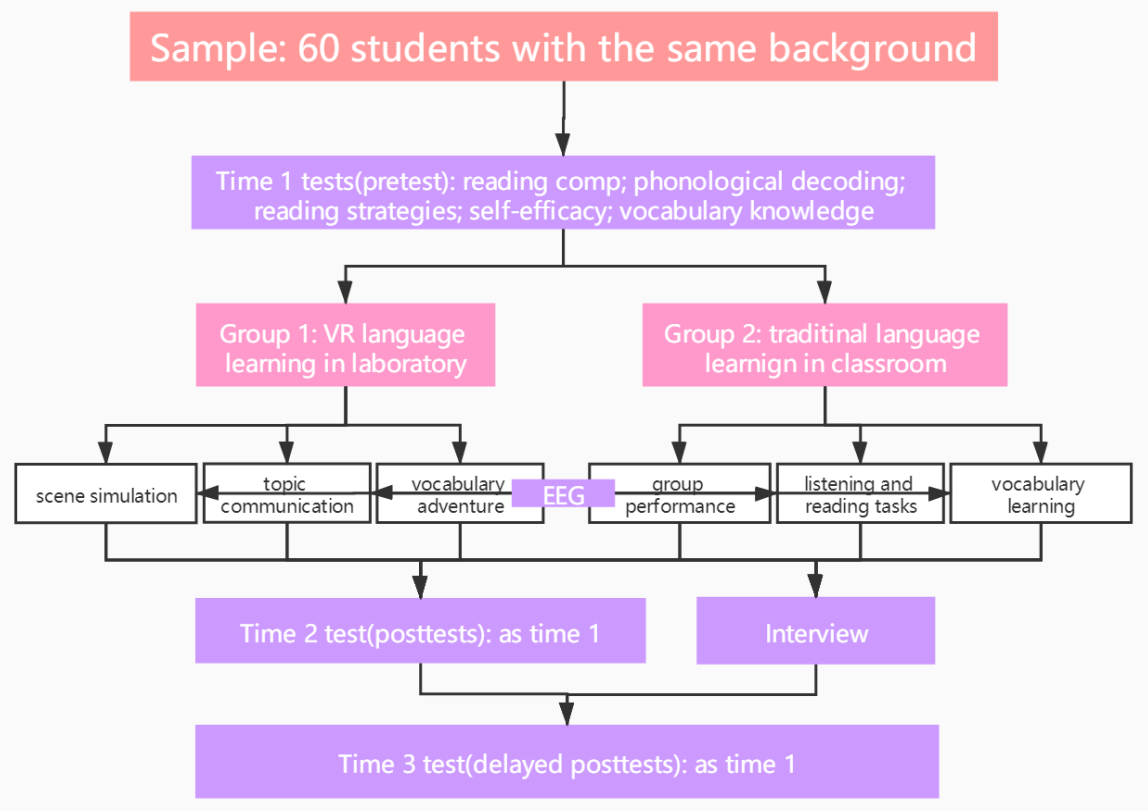

Figure 7: Experiment Design

\subsection{Experiment Design}

\subsubsection{Context and participants}

Students in two parallel classes of the same university are the study's participants, being divided into two groups, using VR language learning laboratory and traditional learning method each. The test content is referred to the learning materials of IELTS (International English Language Testing System) including listening, reading, writing and speaking (see Attachment A). The evaluation will also refer to the test itself, including fluency and coherence, lexical diversity, grammatical diversity and accurate pronunciation. As for the other language, we consider the international standard test as the test reference.

\subsubsection{Experiment steps}

Referred to Figure 7, initially, two groups will take a pretest to differentiate their language levels. Secondly, they will be given the corresponding assignments with different difficulty to learn the second language. As for the experiment group of VR language learning, during the first month practice, the main purpose is to find out each student's unique learning habit, figuring out the preference of each student and continuing their daily learning process in their own way with the help of computer adaptive technology. By using scene simulations such as in a train station asking for directions or ordering at a restaurant, experiment group learning second language in the real situations. Topic communication aims at practicing verbal communication and vocabulary adventure for enlarging the students' vocabulary by virtual reality to simulate an adventure in tropical forest or cave exploration by giving the correct answer of the question they encountered.

As for the control group of traditional language learning, students will follow the teacher's instruction in learning second language and fit for their own language level themselves. Group performance relates to groups of five members giving a creative performance with the same scenes in VR. Listening and reading tasks aims to improve their language intuition, along with vocabulary learning by reciting words and sentences in the way of traditional language leaning.

Despite the three tests of the students for data collection, we also use cerebral neuron radio detector at the same time during the learning process. Students have to wear the equipment to detect their mind signals and biological electrical signal to observe the active intensity. Interviews of five randomly 
selected students in two groups are also recorded and later convert to text for data analysis.

\subsection{Data Analysis Method Design}

We adopt normality and homogeneity of variance assumptions through histograms and normality tests with SPSS, for the sample as a whole and for each group, at the same time points. SPSS has the superiority to perform a wide variety of statistical analyses, both reasoning and theoretical, adopted large scaled researchers and scholars specifically for the purpose of performing statistical analyses. Here the analysis consists of three parts: tests results, mind signals and biological electrical signal detected by cerebral neuron radio detector, and interview records of two groups. With their own standards, we can boldly forecast that there is a significant difference between the two groups. Further data analysis figure is as Figure 8 shows.

\begin{tabular}{|c|c|c|c|c|c|}
\hline & Self-Efficacy & Reading & LK & TERRS & GAP \\
\hline \multicolumn{6}{|c|}{ Self-efficacy } \\
\hline \multicolumn{6}{|c|}{ Reading } \\
\hline \multicolumn{6}{|l|}{ LK } \\
\hline \multicolumn{6}{|l|}{ TERRS } \\
\hline GAP & & & & & \\
\hline
\end{tabular}

Figure 8: Data Analysis

\subsection{Global Case Study}

In terms of the scene simulation, for experiment group, it is based on the virtual reality equipment. Date will be collected from the beginning of the login of the students, going on with the further behavior of the student in the virtual world. In order to complete the given mission, the student has to use his or her own knowledge about the second language to express and make himself or herself understood. Whereas for the control group, the substituted task is group performance, in which some members of the group need to play the role of the computer, structuring the scene for the others, shown in Figure 9.

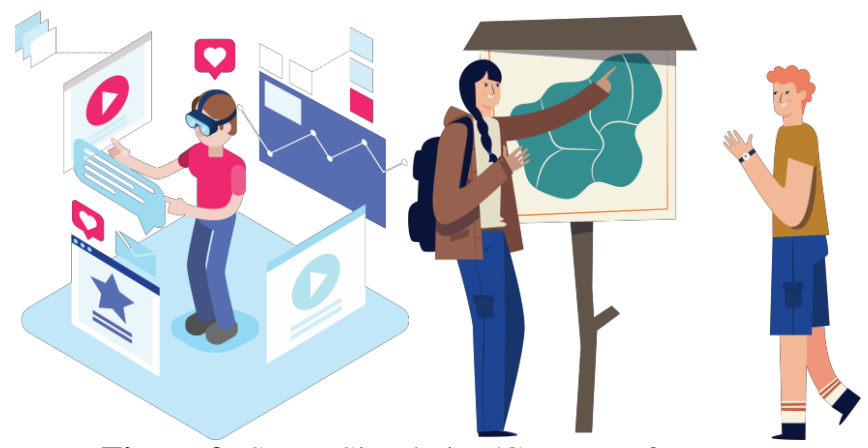

Figure 9: Scene Simulation/Group Performance

Both groups need to wear the electrical equipment for cerebral neuron radio detecting data. On account of the statistics, we can find out whether the virtual reality language learning method has an influence of students' academic performance, learning motivation, self-efficacy, problem-solving tendency and cognitive load. Further study will help to find out the optimum time and frequency of the immersion in the second language environment of virtual reality.

\subsection{Conclusion and Future Plan}

This study has the goal of help students' using virtual reality language learning laboratory to improve their academic performance, learning motivation, self-efficacy as well as problem-solving tendency without add the cognitive load. With deep research and real data, move forward to figure out the optimum time and frequency of the immersion in the second language environment of virtual reality so that the laboratory will demonstrate his value and give students a chance to feel the exotic charm so as to arouse their interests in learning foreign language.

Future plan of this research will need a larger amount of participants for VR laboratory and traditional teaching independently to avoid the biological differences of the students. Developed technology in computer science for education requires the students to develop new skills in operating high-technology equipment that will also require new teaching practices of teachers, which will be new research priorities [12].

\section{Acknowledgements}

The author thanks Dr. WEN speciously for he not only helps polish this article but more importantly emphasizes the significance of the expansion of inner horizons, which influences the author a lot. By completing this article, the author substantially improves the reading skills of English literatures, leading to the enhancement of the English language ability, with which the author will benefit dramatically in the future.

\section{References}

[1] Squire, K. D. Mobile media learning: Multiplicities of place[J]. Horizon, Volume 17, 2009, Pages 70-80.

[2] Julie M. Sykes. Digital games and language teaching and learning[J]. Foreign Language Annals, Volume 51, 2018, Issue 1.

[3] Yifan Wang, Kiran Ijaz, Dong Yuan, Rafael A. Calvo1. VR-Rides: An object-oriented application framework for immersive virtual reality exergames[J]. Software: Practice and Experience, Volume 50, 2020, Issue 7.

[4] Li Wei Chen, Jo Peng Tsai, Yung Chou Kao, Yu Xian $\mathrm{Wu}$. Investigating the learning performances between sequence and context based teaching designs for virtual reality (VR) based machine tool operation training $[\mathrm{J}]$. Computer Applications in Engineering Education, Volume 27, 2019, Issue 5.

[5] Janus S. Liang. Modeling an Immersive VR Driving Learning Platform in a Web-Based Collaborative Design Environment $[\mathrm{J}]$. Computer Applications in Engineering Education, Volume 20, 2012, Issue 3.

[6] Jyun Chen Chen, Yun Huang, Kuen Yi Lin, Yu Shan Chang, Hung Chang Lin, Chien Yu Lin, Hsien Sheng Hsiao. Developing a hands on activity using virtual reality to help students learn by doing[J]. Journal of Computer Assisted Learning, Volume 36, 2019, Issue 1.

[7] T.-Y. Liu. A context-aware ubiquitous learning environment for language listening and speaking $[\mathrm{J}]$. 
Journal of Computer Assisted Learning, Volume 25, 2009, Issue 6.

[8] Shao-Chen Chang, Ting-Chia Hsu, Wei-Chen Kuo and Morris Siu-Yung Jong. Effects of applying a VR-based two-tier test strategy to promote elementary students' learning performance in a Geology class $[\mathrm{J}]$. British Journal of Educational Technology, Volume 51, 2019, Issue 1.

[9] Ching Huei Chen, Hsiu-Ting Hung, Hui-Chin Yeh. Virtual reality in problem-based learning contexts: Effects on the problem-solving performance, vocabulary acquisition and motivation of English language learners $[\mathrm{J}]$. Journal of Computer Assisted Learning, Volume 37, 2021, Issue 3.

[10] Andrea Vogt, Franziska Babel, Philipp Hock, Martin Baumann, Tina Seufert. Immersive virtual reality or auditory text first? Effects of adequate sequencing and prompting on learning outcome[J]. British Journal of Educational Technology, 2021, Early View.

[11] Nadira Saab, Wouter R. van Joolingen, Bernadette H. A. M. van Hout-Wolters. Communication in collaborative discovery learning $[\mathrm{J}]$. British Journal of Educational Psychology, Volume 75, 2010, Issue 4.

[12] Carl Blyth. Immersive technologies and language learning[J]. Foreign Language Annals, Volume 51, 2018 , Issue 1 . 